\title{
Socioeconomic inequalities in dental behaviors among Korean adults
}

\section{Wpływ statusu socjoekonomicznego na zachowania prozdrowotne dotyczące jamy ustnej wśród dorosłych mieszkańców Korei}

\author{
Sun-Young Chung ${ }^{1, A-F}$, Sang-Yoon Chung ${ }^{2, A-E}$, Young-Hye Hwang ${ }^{3, A-D}$, Eun-Kyong Kim ${ }^{4, B, C}$, Youn-Hee Choi ${ }^{5, B, C}$, Keun-Bae Song $5, B, E, F$ \\ ${ }^{1}$ Department of Preventive Dentistry, Dankook University Dental Hospital, Choongnam, Korea \\ 2 Department of Internal Medicine, College of Medicine, Korea University, Seoul, Korea \\ ${ }^{3}$ Department of Conservative Dentistry, Seoul Dental Hospital of Disabled, Seoul, Korea \\ ${ }^{4}$ Department of Dental Hygiene, College of Science \& Technology, Kyungpook National University, Gyeongbuk, Korea \\ 5 Department of Preventive Dentistry, School of Dentistry, Kyungpook National University, Daegu, Korea \\ A - research concept and design; $\mathrm{B}$ - collection and/or assembly of data; $\mathrm{C}$ - data analysis and interpretation; \\ $D$ - writing the article; $E$ - critical revision of the article; $F$ - final approval of article
}

Address for correspondence

Keun-Bae Song

E-mail: kbsong@knu.ac.kr

Funding sources

none declared

Conflict of interest

none declared

Received on June 12, 2017

Revised on June 25, 2017

Accepted on July 25, 2017

DOI

$10.17219 / \mathrm{dmp} / 76082$

Copyright

() 2017 by Wroclaw Medical University

and Polish Dental Society

This is an article distributed under the terms of the

Creative Commons Attribution Non-Commercial License

(http://creativecommons.org/licenses/by-nc-nd/4.0/)

\section{Abstract}

Background. Few studies have tried to investigate the influence of socioeconomic inequalities on dental behaviors by considering the income and education levels as different dimensions of the independent variables in the adult Korean population.

Objectives. This study aimed to evaluate the association between income level and education level in relation to dental behaviors, such as self-cares and dental visits in the adult Korean population.

Material and methods. Six levels of socioeconomic status were classified according to a combination of monthly household income and educational achievement levels. The regression models were built to assess the association between different levels of socioeconomic status and the frequency of tooth brushing and the most recent dental visits.

Results. This study confirmed that high levels of monthly household income and educational achievement were independently related to frequent tooth brushing and frequent dental visits. Low levels of socioeconomic status were inversely related to the frequency of tooth brushing and socioeconomic status groups except for the lowest one were also adversely related to frequent dental visits after adjusting for confounders.

Conclusions. Korean adults with lower incomes but with higher education showed better dental behavior, including tooth brushing and dental visits than those with higher incomes but with lower education. The findings of this study could help in acknowledging the different characteristics of income and education as contributing factors leading to oral health behaviors in the adult Korean population.

Key words: education, income, socioeconomic inequalities, dental behaviors, Koreans, adults

Słowa kluczowe: wykształcenie, dochody, nierówności socjoekonomiczne, zachowania dentystyczne, Koreańczycy, osoby dorosłe 
Inequality in health is universally recognized as a major problem. ${ }^{1-3}$ Numerous studies have investigated socioeconomic inequalities in oral health with various conceptual frameworks ${ }^{4-7}$ and theoretical models. ${ }^{8-10}$ These theoretical models commonly describe oral health-related behaviors within the framework of socioeconomic status based on the social structure and the social environment to predict oral health status. , $, 6,11$

In Andersen's behavioral models, ${ }^{12,13}$ income and education had been regarded as different dimensions that determined dental behaviors such as health service utilization and personal health practices. Education was considered a predisposing characteristic that existed before disease and affected the propensity to seek dental care, while income was considered an enabling characteristic that affects an individual's ability to access the health care system by reducing financial barriers.

Several studies have demonstrated an inverse relationship between unfavorable health-related behaviors and oral health in the context of socioeconomic disparities, ${ }^{11,14-24}$ which used various indicators for socioeconomic status such as the Index of Relative Socioeconomic Disadvantage (IRSD), ${ }^{14}$ the poverty-income ratio, ${ }^{15}$ and the Socioeconomic Disadvantage Index (SDI). ${ }^{16}$ However, other studies have utilized household income ${ }^{18}$ and/or head of household's social class. ${ }^{17}$ For Korean adolescents, Jung et al. employed the Family Affluence Scale (FAS) to demonstrate the association between socioeconomic status and health-enhancing and health-comprising dental behaviors. ${ }^{20}$ Various attempts to clarify the association between socioeconomic inequality and oral health related behaviors have also been made by clustering oral health behaviors. ${ }^{23,24}$

To identify the socioeconomic disparities in dental behaviors that play an important role on oral health status, the authors of this study selected income and education factors that represent different dimensions of "causes of the causes" leading to oral health outcomes based on Andersen's behavioral models. ${ }^{11,12}$ Each of the two variables as well as the combination of those components were utilized as independent variables. Until now, within the adult Korean population, few studies have tried to investigate the influence of socioeconomic inequalities on the frequency of tooth brushing and visits to dental clinics by considering income and education levels as different dimensions of independent variables.

\section{Objectives}

This study aimed to evaluate the association between monthly household income levels and educational achievement levels with oral health behaviors, such as the frequency of tooth brushing and the most recent dental visits, using a national representative sample for adult populations from South Korea.

\section{Material and methods}

The data was obtained from the 2006 Korean National Oral Health Survey (KNOHS), which surveyed 15,777 Koreans, of whom 4,546 were aged 18 years and older and had completed the interview questions. After excluding 663 records with missing values for the variables used in this study, 3,883 records were analyzed and were weighted to represent the whole population of Korean adults. ${ }^{25}$ All participating individuals provided written informed consent and this study was conducted in accordance with the ethical principles of the Helsinki declaration. The study protocols were reviewed and approved by the Institutional Review Board of the Kyungpook National University in Daegu, Korea (approval number: 2016-0068).

Eight trained interviewers collected information on the participants' characteristics using standardized questionnaires. To describe the characteristics of the study population, the demographic information was investigated: age, gender, educational attainment, monthly household income, and residential area. Oral health-related behaviors included the frequency of tooth brushing, the use of dental care services (the time of the most recent dental checkups and the purpose of the most recentness of dental visits), and smoking.

Educational attainment was categorized into no formal education, 1 to 9 years of schooling, 10 to 12 years of schooling, and more than 12 years of schooling. Monthly household income was divided into 4 segments: low, middle-low, middle-high, and high. The cut-off points for each income segment were 1,090 US dollars (USD), 2,246 USD, and 3,575 USD. One US dollar was 925.80 Korean Won Currency (KRW) in December 2006.

Six levels of socioeconomic status were classified according to a combination of 4 income and 4 education categories: LEVEL 1 as low incomes with non-formal education group; LEVEL 2 as low or middle-low incomes with 0-9 years of schooling groups excluding LEVEL 1;

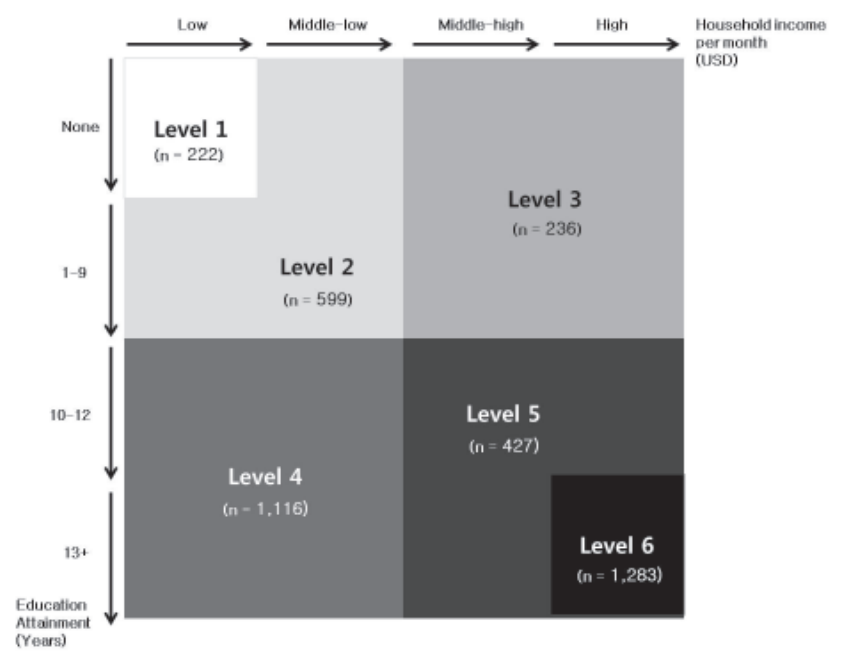

Fig. 1. Six levels of socioeconomic status from LEVEL 1 to LEVEL 6 according to a combination of monthly household income and educational achievement levels $(\mathrm{N}=3.883)$ 
Table 1. The distribution of the study population according to the levels of monthly household income and educational attainment $(\mathrm{N}=3,883)$

\begin{tabular}{|c|c|c|c|c|c|}
\hline \multirow{2}{*}{$\begin{array}{l}\text { Education attainment } \\
\text { (years) }\end{array}$} & \multicolumn{4}{|c|}{ Household income per month (USD)* } & \multirow{2}{*}{ Total } \\
\hline & low & middle-low & middle-high & high & \\
\hline None & $222(67.6)+(15.9) \neq$ & $51(15.5) \dagger(2.6) \neq$ & $24(7.8)+(1.2) \neq$ & $25(9.1) \dagger(1.5) \neq$ & $322(100.0)+(4.4) \neq$ \\
\hline $1-9$ & $350(42.8)+(27.4) \ddagger$ & 198 (29.0)† (13.3)‡ & $101(17.5) \dagger(7.3) \neq$ & $86(10.7) \dagger(4.9) \neq$ & $735(100.0)+(12.0) \neq$ \\
\hline $10-12$ & $300(14.8)+(36.4) \neq$ & $501(30.0) \dagger(53.0) \neq$ & $516(31.5)+(50.6) \neq$ & $433(23.7) \dagger(41.8) \neq$ & $1,750(100.0)+(46.2) \neq$ \\
\hline $13+$ & $94(10.2)+(20.3) \ddagger$ & $221(21.8)+(31.1) \neq$ & $334(31.6)+(40.9) \neq$ & $427(36.4) \dagger(51.8) \neq$ & $1,076(100.0)+(37.3) \neq$ \\
\hline Total & $966(18.8)+(100.0) \neq$ & $971(26.2)+(100.0) \neq$ & 975 (28.8)† (100.0)‡ & $971(26.2)+(100.0) \neq$ & $3,883(100.0)+\ddagger$ \\
\hline
\end{tabular}

n - unweighted number, \% - weighted percent; * Cut-off points were 1,090 USD, 2,246 USD, and 3,573 USD in order; † Row percent; $\neq$ Column percent.

LEVEL 3 as middle-high or high incomes with 0-9 years of schooling groups; LEVEL 4 as low or middle-low incomes with 10 or more years of schooling groups; LEVEL 6 as a high incomes with 13 or more years of schooling group; and LEVEL 5 as middle-high or high incomes and 10 or more years of schooling groups excluding LEVEL 6 (Table 1 and Fig. 1).

Dental behaviors employed in the analyses were the frequency of tooth brushing and the time of the most recent dental visit. The frequent tooth brushing and the most recent dental visit were defined as 3 times or more per day and the dental visits within 1 year, respectively.

Data management was performed by Surveyfreq and Surveylogistic procedures using SAS 9.1.3 (SAS Institute Inc., Cary, NC, USA). Four logistic regression models were built to assess the relationship between different levels of socioeconomic status and the frequency of tooth brushing and the time of the most recent dental visits. Model 1 generated a crude association, model 2 generated the association after controlling for age alone, model 3 generated the association after controlling for another dental behavior, and finally, model 4 calculated the association after controlling for both of age and other dental behavior as confounding factors. p-values were calculated by Surveyfreq procedures and odds ratios (ORs) with 95\% confidence intervals were estimated by Surveylogistic procedures.

\section{Results}

The average age of the study population was 42.5 years old (range from 18 to 91). Half of the respondents brushed their teeth twice a day and approximately $40 \%$ did so 3 times or more. About $40 \%$ of the subjects had visited dental clinics within 1 year. Of the 1,445 respondents who answered the questionnaire about the purpose of the recent dental visits, only $20 \%$ visited the dental clinic for preventive purposes. One quarter of the subjects had a regular smoking habit (Table 2).

High levels of monthly household income and educational achievement were independently related to the frequent tooth brushing and the frequent dental visits. More than $15 \%$ of the participants with no education had brushed their teeth more than 3 times a day, and the pro- portion of the frequent tooth brushing increased as the level of education increased. The frequent dental checkups also increased with the level of education. About a quarter of individuals in the lowest income group brushed their

Table 2. The characteristics of the study population $(N=3,883)$

\begin{tabular}{|c|c|c|c|}
\hline \multicolumn{3}{|c|}{ Study population } & Total $(\mathrm{n}=3.883)$ \\
\hline \multicolumn{4}{|c|}{ Biological factor } \\
\hline \multirow{6}{*}{\multicolumn{2}{|c|}{ Age groups }} & $18-29$ & $467(23.0)$ \\
\hline & & $30-39$ & $925(25.2)$ \\
\hline & & $40-49$ & $722(21.2)$ \\
\hline & & $50-59$ & $610(14.5)$ \\
\hline & & $60-69$ & $635(10.0)$ \\
\hline & & $\geq 70$ & $524(6.1)$ \\
\hline \multirow{2}{*}{\multicolumn{2}{|c|}{ Gender }} & male & $1.410(47.1)$ \\
\hline & & female & $2.473(52.9)$ \\
\hline \multicolumn{4}{|c|}{ Socioeconomic factor } \\
\hline \multirow{4}{*}{\multicolumn{2}{|c|}{ Education (years) }} & none & $322(4.4)$ \\
\hline & & $1-9$ & $735(12.0)$ \\
\hline & & $10-12$ & $1.750(46.3)$ \\
\hline & & $13+$ & $1.076(37.3)$ \\
\hline \multirow{4}{*}{\multicolumn{2}{|c|}{ Monthly household income* }} & low & $966(18.8)$ \\
\hline & & middle-low & $971(26.2)$ \\
\hline & & middle-high & $975(28.8)$ \\
\hline & & high & $971(26.2)$ \\
\hline \multirow{3}{*}{\multicolumn{2}{|c|}{ Area }} & metropolis & $1.545(48.2)$ \\
\hline & & city & $1.839(36.6)$ \\
\hline & & rural & $499(15.2)$ \\
\hline \multicolumn{4}{|c|}{ Oral health-related behaviors } \\
\hline \multirow{3}{*}{\multicolumn{2}{|c|}{$\begin{array}{l}\text { Frequency of tooth brushing } \\
\text { (times/day) }\end{array}$}} & 0 & $48(0.8)$ \\
\hline & & 1 & $456(10.2)$ \\
\hline & & 2 & $1.937(50.1)$ \\
\hline \multirow{5}{*}{$\begin{array}{l}\text { Use of } \\
\text { dental } \\
\text { care } \\
\text { service }\end{array}$} & \multirow{3}{*}{$\begin{array}{l}\text { Recent dental checkups } \\
\text { (years) }\end{array}$} & $<1$ & $1.570(40.9)$ \\
\hline & & $1-2$ & $830(21.5)$ \\
\hline & & $>2$ & $1.483(37.6)$ \\
\hline & \multirow{2}{*}{$\begin{array}{l}\text { Purpose of recent dental } \\
\text { visit }(n=1.445)\end{array}$} & prevention & 263(20.5) \\
\hline & & treatment & $1.182(79.5)$ \\
\hline \multirow{2}{*}{\multicolumn{2}{|c|}{ Smoking }} & yes & $729(25.1)$ \\
\hline & & no & $3.154(74.9)$ \\
\hline
\end{tabular}

$\mathrm{n}$ - unweighted number, \% - weighted percent; * Cut-off points were 1.090 USD, 2.246 USD, and 3.573 USD in order. 
teeth 3 times or more per day, and the proportion of people getting dental check-ups within one year increased along with the level of monthly household income (Fig. 2).

Lower levels of socioeconomic status were inversely related to frequent tooth brushing. The ORs for more than 3 times tooth brushing per day increased with the gradients of income and education except for LEVEL 3 (middle-high or high income with less than a 10 year-education) and was statistically significant at each level. The ORs for tooth brushing frequencies were a bit increased after controlling for all confounders, and the linear relationship was slightly attenuated compared to a crude association (Table 3).

Lower levels of socioeconomic status were also adversely related to the frequent dental visits. The ORs for having dental visits within one year increased with the gradients of income and education except for LEVEL 1 (low income with no education) and was statistically significant at each level. A linear association became clear after controlling for the confounders, especially age, but was still interrupted by LEVEL 1 (Table 4).

\section{Discussion}

The results from this study are consistent with previous studies that manifested an association between socioeconomic status and oral health-related behaviors. ${ }^{15,16,20,26}$ Aleksejuniene et al. indicated that socioeconomic status has a significant effect on oral hygiene behaviors and dental visit patterns using structural equation modeling. ${ }^{26}$ Sabbah et al. noted that socioeconomic inequalities in health-related behaviors and poorer health-related behaviors were more common among those less educated and those with lower incomes. ${ }^{15}$ Wamala et al. reported that financial barriers limit access to healthcare services and also contribute to health inequalities, even though people having socioeconomic disadvantages needed dental care, were not afraid of the dentist, and had the time to access dental treatment. ${ }^{16}$

It is noteworthy that Andersen's behavioral models set income and education into separate dimensions, which
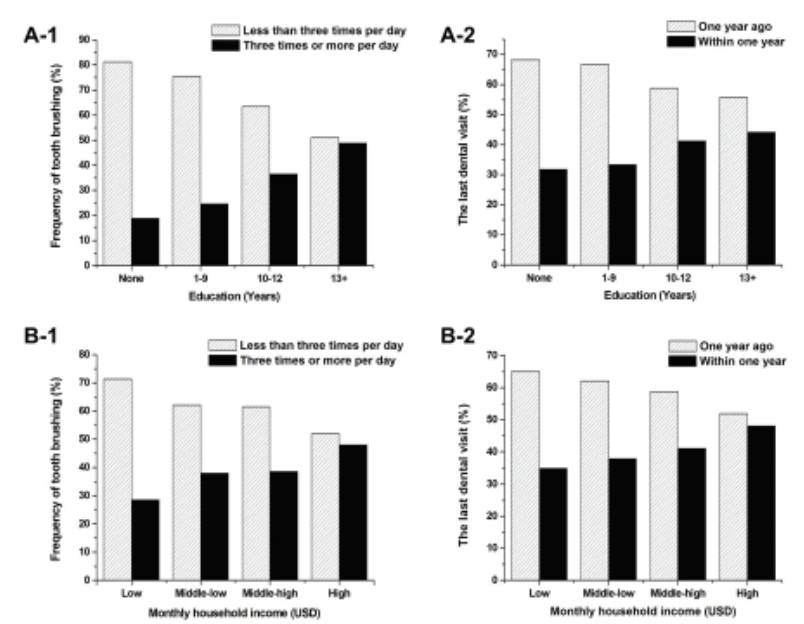

Fig. 2. The proportion of the frequent tooth brushing and the recent dental visits within 1 year according to monthly household income and educational attainment $(\mathrm{N}=3.883)$.

were designated as enabling factors and predisposing factors, although some conceptual frameworks ${ }^{5}$ for analyzing the determinants of dental caries designated income and education as a socioeconomic or sociocultural factor associated with oral health status.

Interestingly, the ORs for the frequent tooth brushing and the recentness of the dental visits were higher at LEVEL 4 than at LEVEL 3 in all regression models. Individuals at LEVEL 4 had lower incomes but were better educated than those at LEVEL 3, and consequently showed better dental behaviors, including tooth brushing and dental checkups. Baldani et al. emphasized education, such as access to school and a regular source of health care, rather than family monthly income as determinants of dental care utilization. $^{21}$

The ORs for the recent dental visits were higher in LEVEL 3 than in LEVEL 2, while those for tooth brushing frequencies were even lower in LEVEL 3 than in LEVEL 2 in all regression models. Thus, these results support the fact that income is a strong and independent predictor of health service utilization. ${ }^{27}$ Previous studies have consistently shown that insured and high-income individuals utilized dental services more frequently than their

Table 3. Associations between the income and education levels and the frequency of daily tooth brushing after adjusting for age and/or the most recent dental visits

\begin{tabular}{|c|c|c|c|c|c|c|c|c|}
\hline \multirow{2}{*}{$\begin{array}{l}\text { Socioeconomic } \\
\text { statistic }\end{array}$} & \multicolumn{2}{|c|}{ Model 1} & \multicolumn{2}{|c|}{ Model 2} & \multicolumn{2}{|c|}{ Model 3} & \multicolumn{2}{|c|}{ Model 4} \\
\hline & OR & $95 \% \mathrm{Cl}$ & OR & $95 \% \mathrm{Cl}$ & OR & $95 \% \mathrm{Cl}$ & OR & $95 \% \mathrm{Cl}$ \\
\hline LEVEL 1 & 0.194 & $0.120-0.315$ & 0.314 & $0.185-0.534$ & 0.203 & $0.125-0.329$ & 0.345 & $0.202-0.588$ \\
\hline LEVEL 2 & 0.302 & $0.222-0.410$ & 0.438 & $0.308-0.624$ & 0.319 & $0.234-0.434$ & 0.483 & $0.339-0.689$ \\
\hline LEVEL 3 & 0.230 & $0.148-0.358$ & 0.328 & $0.204-0.527$ & 0.240 & $0.153-0.375$ & 0.356 & $0.220-0.574$ \\
\hline LEVEL 4 & 0.532 & $0.411-0.690$ & 0.577 & $0.442-0.752$ & 0.551 & $0.425-0.715$ & 0.604 & $0.463-0.788$ \\
\hline LEVEL 6 & 1.000 & - & 1.000 & - & 1.000 & - & 1.000 & - \\
\hline
\end{tabular}

OR - odds ratio, Cl - confidence intervals; Model 1 - crude association; Model 2 - adjusting for age; Model 3 - adjusting for the most recent dental visits; Model 4 - adjusting for age and the most recent dental visits. 
Table 4. Associations between income and education levels and the most recent dental visits after adjusting for age and/or the frequency of daily tooth brushing

\begin{tabular}{|c|c|c|c|c|c|c|c|c|}
\hline \multirow{2}{*}{$\begin{array}{l}\text { Socioeconomic } \\
\text { statistic }\end{array}$} & \multicolumn{2}{|c|}{ Model 1} & \multicolumn{2}{|c|}{ Model 2} & \multicolumn{2}{|c|}{ Model 3} & \multicolumn{2}{|c|}{ Model 4} \\
\hline & OR & $95 \% \mathrm{Cl}$ & OR & $95 \% \mathrm{Cl}$ & OR & $95 \% \mathrm{Cl}$ & OR & $95 \% \mathrm{Cl}$ \\
\hline LEVEL 1 & 0.536 & $0.359-0.800$ & 0.334 & $0.210-0.530$ & 0.603 & $0.402-0.905$ & 0.363 & $0.228-0.578$ \\
\hline LEVEL 2 & 0.469 & $0.350-0.629$ & 0.324 & $0.231-0.455$ & 0.514 & $0.383-0.691$ & 0.346 & $0.246-0.485$ \\
\hline LEVEL 3 & 0.548 & $0.372-0.806$ & 0.385 & $0.253-0.585$ & 0.611 & $0.412-0.904$ & 0.418 & $0.274-0.640$ \\
\hline LEVEL 4 & 0.631 & $0.487-0.817$ & 0.579 & $0.444-0.753$ & 0.663 & $0.512-0.860$ & 0.606 & $0.465-0.790$ \\
\hline LEVEL 5 & 0.786 & $0.612-1.010$ & 0.728 & $0.566-0.936$ & 0.817 & $0.636-1.049$ & 0.753 & $0.585-0.970$ \\
\hline LEVEL 6 & 1.000 & - & 1.000 & - & 1.000 & - & 1.000 & - \\
\hline
\end{tabular}

OR - odds ratio, Cl - confidence intervals; Model 1 - crude association; Model 2 - adjusting for age; Model 3 - adjusting for the most recent dental visits; Model 4 - adjusting for age and the most recent dental visits.

counterparts. ${ }^{28}$ It is obvious that potential access is simply defined as the presence of enabling resources. Having enabling resources provides the means for use of services, and increases the likelihood that service use will take place. ${ }^{12}$ In addition, the fact that the ORs for the frequency of brushing particularly dropped in LEVEL 3 implies that frequency of tooth brushing does not increase as incomes rise in groups with less than 10 years of schooling. It is also noteworthy that even more than $15 \%$ of nonregularly educated participants brush their teeth three times or more per day. This phenomenon may be related to the tooth brushing campaigns in Korea which highlight at tooth brushing least 3 times per day after each meal. ${ }^{29}$

The present study found that the higher ORs were shown in LEVEL 1 compared to LEVEL 2 in the association between various socioeconomic statuses and recent dental visits. This result was in accordance with the result of a similar study for the adolescent Korean population. Jung et al. reported that the linear association between socioeconomic status and visiting a dental clinic was interrupted with the lowest FAS score of 0 , since subjects with a score of 0 had visited dental clinics more frequently than those with a score of 1 or $2 .{ }^{20}$ The authors of the present study postulated reasons why a similar phenomenon had also occurred. Individuals belonging to the lowest level of socioeconomic status were more likely to have poor oral health consequences that led to more frequent dental treatment. The authors' assumption is closely related to the limitations of this study.

A major problem of this study is its cross-sectional design. Findings from this study provide only an association between the exposure and outcome variables and do not allow causal inference. This study employed the combination of income levels and education levels as indicators of socioeconomic status, instead of a new indicator of individual socioeconomic status. In addition, the cut-off points for income levels were calculated within the study population so that those figures might not actually reflect income distributions for Korean adults but only showed the distributions for the participants of the present study, even though the dataset was a large national sample of the adult Korean population.
In spite of its limitations, this study confirmed the socioeconomic inequalities associated with dental behaviors in the adult Korean population. Almost linear patterns were shown between the levels of income and education and dental behaviors such as tooth brushing frequencies and the recent dental visits. In addition, the total monthly family income and educational attainment were found to be different predictive variables each being related to dental behaviors, one as an enabling factor and the other as a predisposing factor. Indeed, 3,883 records included in this analysis may not be sufficient to represent the adult Korean population, but these are valuable as an early national survey conducted by the Korean government. In addition, the results of this study will serve as a basis for analyzing dental behavior patterns of the Korean adults from past to present.

Numerous studies have been conducted to improve oral health status and effective implications have been suggested over the world. ${ }^{3,30}$ Further studies are needed to provide more information on individual and contextual determinants of dental behaviors, both of which play an important role in the oral health status of the Korean population.

\section{Conclusions}

High levels of monthly household income and educational achievement were independently related to frequent tooth brushing and the recentness of the dental visits in the adult Korean population. Low levels of socioeconomic status were inversely related to the frequency of tooth brushing and of these, except for the lowest one, were also adversely related to the most recent dental visits. Interestingly, individuals with lower incomes but with higher education showed better dental behaviors including tooth brushing and dental visits than those with higher incomes but with lower education. The findings of this study could help in acknowledging the different characteristics of income and education as contributing factors leading to oral health behaviors in the adult Korean population. 


\section{References}

1. Commission on Social Determinants of Health. Closing the gap in a generation: Health equity through action on the social determinants of health. World Health Organization, Geneva, 2008.

2. Sabbah W, Tsakos G, Chandola T, Sheiham A, Watt RG. Social gradients in oral and general health. J Dent Res. 2007;86:992-996.

3. Tellez M, Zini A, Estupiñan-Day S. Social determinants and oral health: An update. Curr Oral Health Rep. 2014;1:148-152.

4. Andersen RM, Davidson PL. Ethnicity, aging, and oral health outcomes: a conceptual framework. Adv Dent Res. 1997;11:203-209.

5. Petersen PE. Sociobehavioural risk factors in dental caries - international perspectives. Community Dent Oral Epidemiol. 2005;33:274-279.

6. Sanders AE, Slade GD, Turrell G, John Spencer A, Marcenes W. The shape of the socioeconomic-oral health gradient: implications for theoretical explanations. Community Dent Oral Epidemiol. 2006;34:310-319.

7. Tsakos G, Demakakos P, Breeze E, Watt RG. Social gradients in oral health in older adults: findings from the English longitudinal survey of aging. Am J Public Health. 2011;101:1892.

8. Sisson KL. Theoretical explanations for social inequalities in oral health. Community Dent Oral Epidemiol. 2007;35:81-88.

9. Baker SR. Applying Andersen's behavioural model to oral health: What are the contextual factors shaping perceived oral health outcomes? Community Dent Oral Epidemiol. 2009;37:485-494.

10. Newton JT, Bower EJ. The social determinants of oral health: new approaches to conceptualizing and researching complex causal networks. Community Dent Oral Epidemiol. 2005;33:25-34.

11. Sanders AE. Social determinants of oral health: Conditions linked to socioeconomic inequalities in oral health in the Australian population. Australian Research Centers for Population Oral Health, The University of Adelaide, Adelaide, 2007.

12. Andersen RM. Revisiting the behavioral model and access to medical care: Does it matter? J Health Soc Behav. 1995;36:1-10.

13. Andersen R, Newman JF. Societal and individual determinants of medical care utilization in the United States. Milbank Q. 2005;83:1-28.

14. Sanders AE, Spencer AJ, Slade GD. Evaluating the role of dental behaviour in oral health inequalities. Community Dent Oral Epidemiol. 2006;34:71-79.

15. Sabbah W, Tsakos G, Sheiham A, Watt RG. The role of health-related behaviors in the socioeconomic disparities in oral health. Soc Sci Med. 2009;68:298-303.

16. Wamala S, Merlo J, Bostrom G. Inequity in access to dental care services explains current socioeconomic disparities in oral health: The Swedish National Surveys of Public Health 2004-2005. J Epidemiol Community Health, 2006;60:1027-1033.

17. Donaldson AN, Everitt B, Newton T, Steele J, Sherriff M, Bower E. The effects of social class and dental attendance on oral health. J Dent Res. 2008;87:60-64.

18. Brennan DS, Spencer AJ, Roberts-Thomson KF. Dental self-care and visiting behaviour in relation to social inequality in caries experience. Community Dent Health, 2011;28:216-221.

19. Gao XL, Hsu CY, Xu YC, Loh T, Koh D, Hwarng HB. Behavioral pathways explaining oral health disparity in children. $J$ Dent Res. 2010;89:985-990.

20. Jung SH, Tsakos G, Sheiham A, Ryu JI, Watt RG. Socio-economic status and oral health-related behaviours in Korean adolescents. Soc Sci Med. 2010;70:1780-1788.

21. Baldani MH, Mendes YBE, de Campos Lawder JA, de Lara API, da Silva Rodrigues MMA, Antunes JLF. Inequalities in dental services utilization among Brazilian low-income children: The role of individual determinants. J Public Health Dent. 2011;71:46-53.

22. Okullo I, Astrom AN, Haugejorden O. Social inequalities in oral health and in use of oral health care services among adolescents in Uganda. Int J Paediatr Dent. 2004;14:326-335.

23. Singh A, Rouxel P, Watt RG, Tsakos G. Social inequalities in clustering of oral health related behaviors in a national sample of British adults. Prev Med. 2013;57:102-106.

24. Kino S, Bernabé E, Sabbah W. Socioeconomic inequality in clusters of health-related behaviours in Europe: Latent class analysis of a cross-sectional European survey. BMC Public Health, 2017;17.

25. Ministry of Health and Welfare. Korean National Oral Health Survey 2006. Ministry of Health and Welfare, Seoul, 2007.
26. Aleksejuniene J, Holst D, Grytten Jl, Eriksen HM. Causal patterns of dental health in populations. An empirical approach. Caries Res. 2002;36:233-240.

27. Lasser KE, Himmelstein DU, Woolhandler S. Access to care, health status, and health disparities in the United States and Canada: results of a cross-national population-based survey. Am J Public Health. 2006;96:1-8.

28. Bhatti T, Rana Z, Grootendorst P. Dental insurance, income and the use of dental care in Canada. J Can Dent Assoc. 2007;73:57.

29. Yang DN, Hwang KS, Kwon HJ, Park YD. New tooth brushing campaign about 1-2-3. Int J Clin Prev Dent. 2015;11:45-50.

30. Watt RG. Social determinants of oral health inequalities: Implications for action. Community Dent Oral Epidemiol. 2012;40:44-48. 